\title{
Visual performance, reading ability and patient satisfaction after implantation of a diffractive trifocal intraocular lens
}

This article was published in the following Dove Press journal:

Clinical Ophthalmology

13 November 2017

Number of times this article has been viewed

Rita Mencucci

Eleonora Favuzza

Orsola Caporossi

Stanislao Rizzo

Department of Surgery and Translational Medicine, Eye Clinic, University of Florence, Florence, Italy
Purpose: To evaluate visual outcome, reading performance, contrast sensitivity, and patient satisfaction after cataract surgery with implantation of a diffractive trifocal intraocular lens (IOL).

Patients and methods: A total of 42 eyes (21 patients) underwent cataract surgery with implantation of the trifocal IOL AT LISA tri 839MP. Visual acuity, contrast sensitivity, and patient satisfaction were evaluated 3 months postoperatively. Reading performance was evaluated at 3 months postoperatively with the MNREAD charts.

Results: All eyes achieved a 3-month postoperative monocular uncorrected distance visual acuity of $0.10 \log$ MAR or better (Snellen 20/25). Likewise, $97.62 \%$ and $85.71 \%$ of eyes achieved a postoperative monocular uncorrected intermediate, and near visual acuity of $0.20 \log$ MAR (Snellen 20/30) or better. All patients achieved postoperative binocular uncorrected distance visual acuity, uncorrected intermediate, and uncorrected near visual acuity of $0.20 \operatorname{logMAR}$ (Snellen 20/30) or better. Mean photopic reading acuity and speed were 0.24 $\pm 0.07 \log$ MAR and $177.61 \pm 20.67$ words per minute, respectively. Postoperative contrast sensitivity values were within the ranges of normality for all spatial frequencies evaluated. Postoperative spectacle independence and patient satisfaction was very high, with most of the patients reporting a good or very good visual quality at far, intermediate, and near distances. All patients would choose the same lens again.

Conclusion: The evaluated trifocal IOL provides an effective restoration of the visual function after cataract surgery, with high levels of distance, intermediate, and near visual acuity, strong reading performance, and patient satisfaction.

Keywords: trifocal, intraocular lens, IOL, reading performance, cataract, presbyopia

\section{Introduction}

Trifocal diffractive intraocular lenses (IOLs) have been developed to provide an improved visual restoration after cataract surgery compared to bifocal diffractive IOLs. ${ }^{1-3}$ Bifocal IOLs indeed might not be able to provide an acceptable spectacle independence for the intermediate distance, and this is becoming more important for patients' everyday activities (computers, tablets ...). ${ }^{1-3}$

Several studies have demonstrated that the generation of a third focal point with an IOL using diffractive optics does not induce an increase in the incidence of visual disturbances or a deterioration of the visual quality. ${ }^{1,4-6}$ Likewise, as trifocal IOLs provide a complete visual restoration, including far, intermediate, and near distances, high levels of patient satisfaction have been reported with them. ${ }^{7-10}$ 
The aim of the current study was to evaluate the visual outcome, contrast sensitivity, reading performance, and satisfaction in patients who underwent cataract surgery with implantation of a specific model of diffractive trifocal IOL. Focus was placed on the evaluation of reading ability as a measure of the importance in the real life of near distance visual performance. Three different reading homologated charts are currently available for reading speed measurement: ${ }^{11}$ the Colenbrander English Continuous Text Near Vision Cards, the MNREAD charts, and the RADNER Reading Charts. In our study, we chose the MNREAD charts because the Italian version was developed at our university. ${ }^{12}$

\section{Materials and methods}

\section{Patients}

This nonrandomized prospective series of cases included 42 eyes of 21 patients who underwent uncomplicated phacoemulsification surgery with bilateral implantation of a diffractive trifocal IOL (AT LISA tri 839MP, Carl Zeiss Meditec, Jena, Germany). Inclusion criteria were patients with cataract and seeking spectacle independence. Exclusion criteria were pseudoexfoliation syndrome, complicated cataract, previous ocular surgery, history of glaucoma or retinal detachment, active ocular disease, macular degeneration or retinopathy, abnormal iris, and irregular corneal astigmatism or regular corneal astigmatism of $>1 \mathrm{D}$. All patients were adequately informed about the study and signed a consent form. The study adhered to the tenets of the Declaration of Helsinki and was approved by the ethics committee of the University of Florence, Italy.

\section{IOL}

The AT LISA tri 839MP IOL is designed to correct aphakia after crystalline lens removal in cataract patients or for presbyopia correction in patients with or without cataract. AT LISA tri $839 \mathrm{MP}$ is a microincision lens and can be implanted into the capsular bag through a $1.8-\mathrm{mm}$ incision with the BLUEMIXS injector (Carl Zeiss Meditec AG). The diopter range covers $0.0 \mathrm{D}$ to $+32.0 \mathrm{D}$ (in 0.5 diopter increments). The AT LISA tri $839 \mathrm{MP}$ is a diffractive multifocal IOL with three focal points. It has a near addition of +3.33 D and an intermediate addition of $+1.66 \mathrm{D}$, offering a comfortable reading and intermediate distance vision of approximately $40 \mathrm{~cm}$ and $80 \mathrm{~cm}$, respectively. The IOL is made of hydrophilic acrylic with hydrophobic surface properties and with an ultraviolet absorber. The aspheric AT LISA tri 839MP is aberration-correcting to reduce and compensate for corneal spherical aberrations.

\section{Examination protocol}

A complete preoperative ophthalmological examination was performed in all cases, including subjective refraction, measurement (by Early Treatment Diabetic Retinopathy Study charts) of monocular and binocular uncorrected distance visual acuity (UDVA) and corrected distance visual acuity (CDVA), uncorrected intermediate visual acuity (UIVA) measured at $80 \mathrm{~cm}$, and uncorrected near visual acuity (UNVA) measured at $40 \mathrm{~cm}$, Goldmann applanation tonometry, slit-lamp examination, corneal topography (Sirius, CSO, Italy), optical biometry (IOL Master v.4.3, Carl Zeiss Meditec), and fundoscopy. Postoperatively, patients were evaluated the day after surgery, as well as at 1 and 3 months. The postoperative examination protocol was identical to the preoperative protocol, with the additional evaluation of the reading performance (MNREAD acuity charts, Italian version), the evaluation of contrast sensitivity under photopic $\left(85 \mathrm{~cd} / \mathrm{m}^{2}\right)$ and mesopic conditions $\left(3 \mathrm{~cd} / \mathrm{m}^{2}\right)$ (Optec 6500 FVA, Stereo Optical Co Inc, Chicago, IL, USA), as well as the evaluation of patient satisfaction and spectacle independence by means of a self-developed questionnaire at 3 months.

Binocular reading performance was evaluated with MNREAD reading charts (Italian version) at a distance of $40 \mathrm{~cm}$ under photopic and mesopic light conditions. MNREAD charts include 19 sentences of three lines (60 characters in 10 words) in decreasing size with a range between $+1.3 \log$ MAR and $-0.5 \log$ MAR and steps of $0.1 \log$ MAR. The patients read the chart aloud beginning with the largest characters and continuing to the smallest ones. The reading time was measured in seconds, and the number of errors for each sentence was documented on a score sheet, and subsequently converted in words per minute (wpm), as the unit for reading speed. The following binocular reading parameters were then calculated: reading acuity (RA, logMAR), which is the size of the last correctly read sentence, maximum reading speed (in words per minute $=[60 *(10-$ errors)]/time in seconds), and critical print size, which is the size of the last sentence read correctly at a speed not lower than $90 \%$ with respect to the average reading speed.

The questionnaire included the following items: what is your satisfaction with visual quality at far, intermediate, and near distances? (scale: very good, good, moderate, bad, very bad); would you choose the same lens again? (Yes/No); do you need spectacles at far, intermediate, and near distances? (Yes/No); and how often do you wear spectacles at far, intermediate, and near distances? (scale: never, sometimes, half of the time, mostly, always). 


\section{Surgery}

All surgeries were performed by the same experienced surgeon (RM) using a standard technique of sutureless $2.2-\mathrm{mm}$ phacoemulsification. Before the surgical procedure, topical anesthesia and mydriatic drops were instilled in all cases. A temporal 2.2-mm clear corneal incision and a $5.5-\mathrm{mm}$ circular capsulorrhexis were performed, and after phacoemulsification the IOL was inserted into the capsular bag using a specific injector (BLUEMIXS 180, Carl Zeiss Meditec). A postoperative topical therapy based on a combination of antibiotics and steroids was prescribed to be applied four times daily for 1 week. Nonsteroidal anti-inflammatory drops were applied 3 times just before surgery, and postoperatively 3 times per day for 4 weeks.

\section{Statistical analysis}

Statistics software package SPSS (v 15.0 for Windows, IBM, Armonk, NY, USA) was used for statistical analysis. The Kolmogorov-Smirnov test was used to check the normality of the data distributions. When parametric analysis was possible, the Student's $t$-test for paired data was performed for all parameter comparisons between preoperative and postoperative examinations as well as between consecutive postoperative visits. Otherwise, when parametric analysis was not possible, the Wilcoxon Rank Sum test was applied to assess the significance of differences between examinations. In all cases, the same level of significance $(p<0.05)$ was considered.

\section{Results}

A total of 42 eyes from 21 patients with a mean age of 75.6 years (standard deviation [SD]: 4.4; median: 76.0, range: $65-82$ years) were included in the study. This sample included 5 (23.81\%) males and 16 females (76.19\%). Mean preoperative axial length and anterior chamber depth were $22.98 \mathrm{~mm}$ (SD: 0.78; median: 23.00, range: $22.00-25.00 \mathrm{~mm}$ ) and $2.45 \mathrm{~mm}$ (SD: 0.50; median: 2.00 , range: $2.00-3.00 \mathrm{~mm}$ ), respectively. Mean IOL power was 21.48 D (SD: 1.69; median: 21.00 , range: $15.00-24.00 \mathrm{D})$, with a mean target refraction of $-0.12 \mathrm{D}$ (SD: 0.11; median: -0.11 , range: -0.36 $0.27 \mathrm{D})$. Mean preoperative photopic and mesopic pupil diameters were $3.63 \mathrm{~mm}$ (SD: 0.82; median: 3.72, range: $1.55-4.87 \mathrm{~mm}$ ) and $4.34 \mathrm{~mm}$ (SD: 0.98; median: 4.56, range: $1.80-6.18 \mathrm{~mm})$, respectively.

\section{Visual acuity outcomes}

Table 1 summarizes the monocular visual acuity data during the follow-up. As shown, a significant improvement compared to the preoperative visual acuities was observed in monocular logMAR UDVA, UIVA, UNVA, and CDVA with surgery $(p<0.001)$. All eyes achieved a 3-month postoperative monocular logMAR UDVA of 0.10 (Snellen 20/25) or better. Likewise, $97.62 \%$ and $85.71 \%$ of eyes achieved a postoperative monocular logMAR UIVA and UNVA of 0.20 (Snellen 20/30) or better. Regarding binocular visual acuity data (Table 2), significant improvements compared to the preoperative visual acuities were also observed for all visual acuity parameters, with $100 \%$ of patients achieving a postoperative binocular logMAR UDVA, UIVA, and UNVA of 0.20 (Snellen 20/30) or better (Figure 1). As the subjective refraction was 0 for all patients, distance-corrected intermediate visual acuity (DCIVA) and distance-corrected near visual acuity (DCNVA) were not measured.

\section{Reading performance outcomes}

Table 3 summarizes the binocular reading speed and RA outcomes at 3 month postoperatively. The photopic RA was $0.24 \pm 0.07 \log \mathrm{MAR}$, the critical print size $0.43 \pm 0.09 \log \mathrm{MAR}$, and the maximum reading speed $177.61 \pm 20.67 \mathrm{wpm}$. RA, critical print size, and maximum reading speed were significantly better under photopic conditions compared to mesopic conditions $(p \leq 0.004)$.

Table I Postoperative monocular visual outcome

\begin{tabular}{|c|c|c|c|c|}
\hline & Preoperative & $\begin{array}{l}\text { I month } \\
\text { postoperative }\end{array}$ & $\begin{array}{l}3 \text { months } \\
\text { postoperative }\end{array}$ & $\begin{array}{l}p \text {-value } \\
\text { ( } 3 \text { months vs preop) }\end{array}$ \\
\hline \multirow[t]{2}{*}{ logMAR UDVA } & $0.5 I(0.26)$ & $0.00(0.01)$ & $0.01(0.03)$ & $<0.001$ \\
\hline & $0.49(0.20-1.00)$ & $0.00(-0.06-0.06)$ & $0.00(-0.06-0.15)$ & \\
\hline \multirow[t]{2}{*}{ logMAR UIVA $80 \mathrm{~cm}$} & $0.54(0.28)$ & $0.16(0.07)$ & $0.14(0.06)$ & $<0.001$ \\
\hline & $0.42(0.10-1.20)$ & $0.20(0.00-0.30)$ & $0.12(-0.02-0.26)$ & \\
\hline \multirow[t]{2}{*}{ logMAR UNVA $40 \mathrm{~cm}$} & $0.60(0.25)$ & $0.25(0.06)$ & $0.21(0.05)$ & $<0.001$ \\
\hline & $0.50(0.24-1.10)$ & $0.26(0.10-0.40)$ & $0.20(0.10-0.34)$ & \\
\hline \multirow[t]{2}{*}{ logMAR CDVA } & $0.29(0.15)$ & $0.00(0.01)$ & $0.01(0.03)$ & $<0.001$ \\
\hline & $0.23(0.20-1.00)$ & $0.00(-0.06-0.06)$ & $0.00(-0.06-0.15)$ & \\
\hline
\end{tabular}

Note: Data presented as mean (SD) and median (range).

Abbreviations: SD, standard deviation; UDVA, uncorrected distance visual acuity; UIVA, uncorrected intermediate visual acuity; UNVA, uncorrected near visual acuity; CDVA, corrected distance visual acuity. 
Table 2 Postoperative binocular visual outcome

\begin{tabular}{lllll}
\hline & Preoperative & $\begin{array}{l}\text { I month } \\
\text { postoperative }\end{array}$ & $\begin{array}{l}\text { 3 months } \\
\text { postoperative }\end{array}$ & $\begin{array}{l}\boldsymbol{p} \text {-value } \\
\text { (3 months vs preop) }\end{array}$ \\
\hline logMAR UDVA & $0.30(0.14)$ & $0.00(0.01)$ & $0.00(0.05)$ & $<0.00 \mathrm{I}$ \\
logMAR UIVA $80 \mathrm{~cm}$ & $0.30(0.10-0.60)$ & $0.00(-0.05-0.02)$ & $0.00(-0.06-0.20)$ & $<0.001$ \\
logMAR UNVA 40 cm & $0.40(0.22)$ & $0.13(0.07)$ & $0.11(0.07)$ & $<0.001$ \\
logMAR CDVA & $0.38(0.00-0.90)$ & $0.10(0.00-0.22)$ & $0.10(-0.08-0.20)$ & \\
& $0.50(0.22)$ & $0.21(0.04)$ & $0.18(0.05)$ & $<.20(0.00-0.20)$ \\
\end{tabular}

Note: Data presented as mean (SD) and median (range).

Abbreviations: SD, standard deviation; UDVA, uncorrected distance visual acuity; UIVA, uncorrected intermediate visual acuity; UNVA, uncorrected near visual acuity; CDVA, corrected distance visual acuity.

\section{Contrast sensitivity outcomes}

Figure 2 displays the 3-month postoperative contrast sensitivity function measured under photopic and mesopic conditions. As shown, the photopic contrast sensitivity values were within the ranges of normality as defined in Hohberger et al, ${ }^{13}$ for all spatial frequencies evaluated, except for the 3 cycles per degree (cpd) value which was slightly lower. The mesopic values were within the normal range, except for the 1.5 and 3 cpd values which were slightly lower.

\section{Patient satisfaction and spectacle independence outcomes}

Postoperative patient satisfaction was very high, with most of patients reporting a good or very good visual quality at far, intermediate, and near distances (Figure 3). All patients $(100 \%)$ would choose the same lens again. Postoperative spectacle independence was high at all distances, with none of the patients requiring glasses for performing far and intermediate activities, and $76.2 \%$ of patients not needing or needing only sometimes spectacles for near distance activities (Figure 4).

\section{Complications}

No complications (posterior capsular rupture or anterior capsular tears, intraoperative iris damage, postoperative cystoid macular edema, or postoperative ocular hypertension) occurred during this study.

\section{Discussion}

In the current study, very good monocular distance and intermediate and near visual outcomes were obtained with the evaluated trifocal diffractive IOL, associated with high

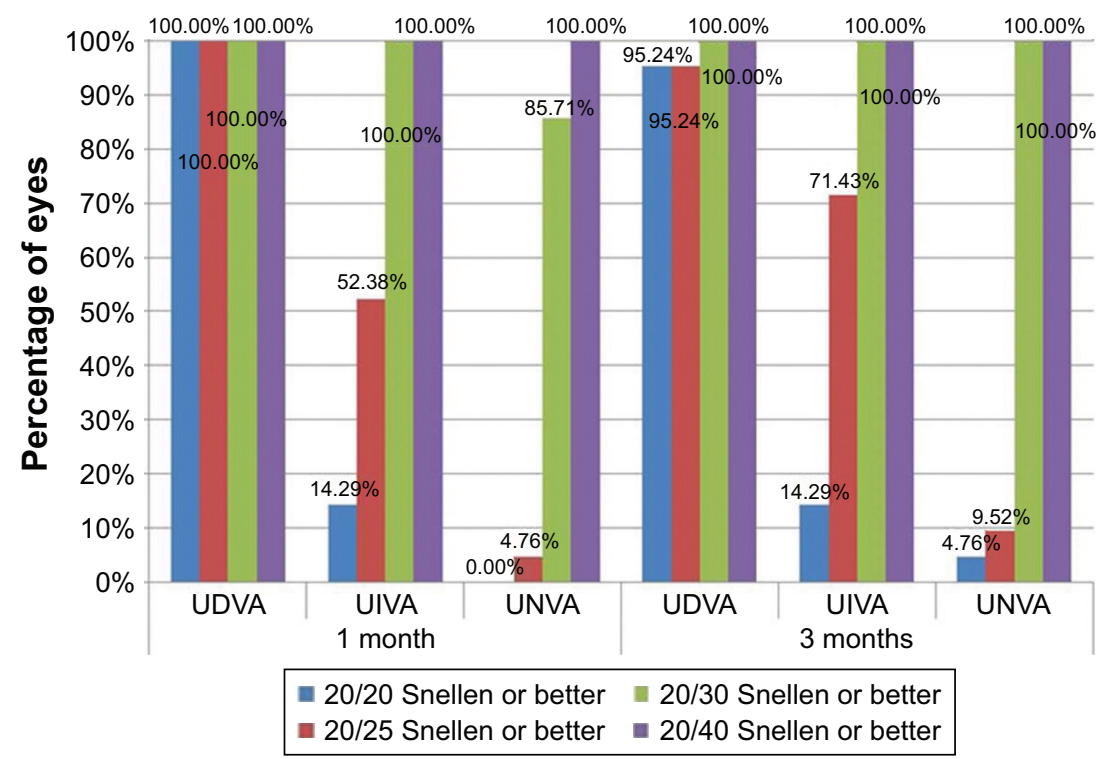

Figure I Distribution of I-month and 3-month postoperative binocular visual outcomes.

Abbreviations: UDVA, uncorrected distance visual acuity; UIVA, uncorrected intermediate visual acuity; UNVA, uncorrected near visual acuity. 
Table 3 Three-month postoperative binocular reading speed and acuity outcomes

\begin{tabular}{llll}
\hline & $\begin{array}{l}\text { Photopic } \\
\text { conditions }\end{array}$ & Mesopic conditions & $p$-value \\
\hline Reading acuity (logMAR) & $0.24(0.07)$ & $0.35(0.09)$ & $<0.001$ \\
& $0.30(0.10-0.30)$ & $0.40(0.20-0.50)$ & $0.54(0.10)$ \\
Critical print size (logMAR) & $0.43(0.09)$ & $0.50(0.30-0.70)$ & $<0.001$ \\
Maximum reading speed (words per minute) & $0.40(0.20-0.60)$ & $160.31(19.22)$ & 0.004 \\
& $177.61(20.67)$ & $162.98(108.95-198.91)$ & \\
\hline
\end{tabular}

Note: Data presented as mean (SD) and median (range).

Abbreviation: SD, standard deviation.

levels of spectacle independence. Mean UDVA, UIVA $(80 \mathrm{~cm})$ and UNVA $(40 \mathrm{~cm})$ values of 0.01 (Snellen 20/20), 0.14 (Snellen 20/27), and 0.21 (Snellen 20/30) logMAR were obtained 3 months after surgery. This is consistent with the visual outcomes reported by Mojzis et a ${ }^{14}$ in a previous series of cases evaluating the results of the same IOL with toricity 3 months after its implantation, with mean logMAR UDVA, UIVA $(80 \mathrm{~cm}$ ), and UNVA $(40 \mathrm{~cm})$ values of 0.03 (Snellen 20/20), 0.08 (Snellen 20/25), and 0.16 (Snellen 20/28), respectively. Likewise, Kretz et a ${ }^{15}$ reported in another study mean 3-month postoperative UDVA, UIVA, and UNVA values of $0.13 \pm 0.15$ (Snellen 20/26), $0.08 \pm 0.15$ (Snellen 20/24), and 0.13 $\pm 0.18 \log$ MAR (Snellen 20/26), respectively. Plaza-Puche et a ${ }^{16}$ reported 3 months after AT LISA tri 839 MP implantation a UDVA of $0.00 \pm 0.07 \log$ MAR (Snellen 20/20) and a UNVA of 0.17 $\pm 0.10 \log$ MAR (Snellen 20/30). In our series, improved binocular visual outcomes compared to monocular outcomes were found, with mean UDVA, UIVA, and UNVA values of 0.00 (Snellen 20/20), 0.11 (Snellen 20/25), and 0.18 (Snellen 20/30) logMAR, respectively. Kretz et a ${ }^{17}$ also reported a statistical significant increase of the binocular visual function at all distances after the implantation of the same trifocal IOL platform as evaluated in our series. In our series, $100 \%$ of patients achieved a

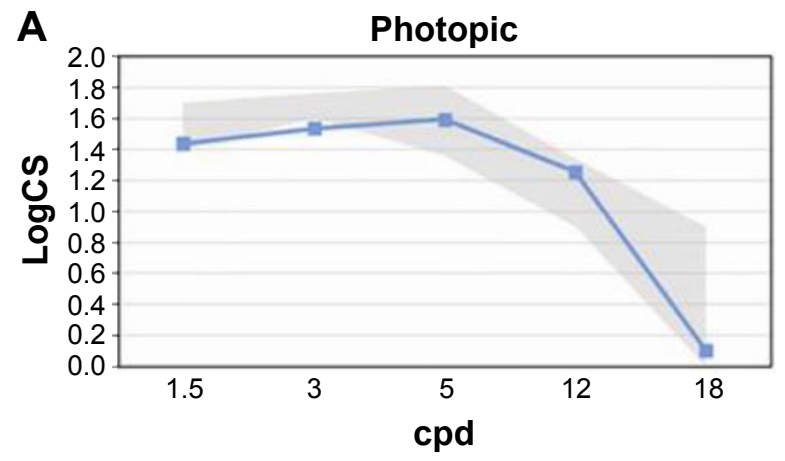

postoperative binocular logMAR UDVA, UIVA, and UNVA of 0.20 (Snellen 20/30) or better.

Even if a comparison between the outcomes of different type of trifocal and bifocal IOLs might be difficult due to the variability of follow-up intervals and testing methods between the published studies ${ }^{18}$ our visual acuity outcomes can be considered in line with that obtained with other trifocal IOL models. ${ }^{16,19}$ A recent meta-analysis ${ }^{18}$ considering prospective clinical trials on trifocal (including two cohort studies on AT Lisa $839 \mathrm{MP}$ ) and bifocal IOLs, found better intermediate visual acuity results with the trifocal IOLs, without significant differences in terms of distance and near visual acuity in comparison with bifocal IOLs. Nevertheless, the results on contrast sensitivity and subjective visual quality were less conclusive. ${ }^{18}$

To our knowledge, no reports have been published about the reading performance of patients implanted with this trifocal IOL. In agreement with the good near visual outcomes obtained in our series, reading speed and RA measured with MNREAD charts were also found to be excellent. Specifically, mean photopic RA at $40 \mathrm{~cm}$ was $0.24 \log$ MAR with a reading speed of $177.61 \mathrm{wpm} 1$ month after surgery and a critical print size of $0.40 \log$ MAR. This is consistent with previous studies showing the positive impact of different

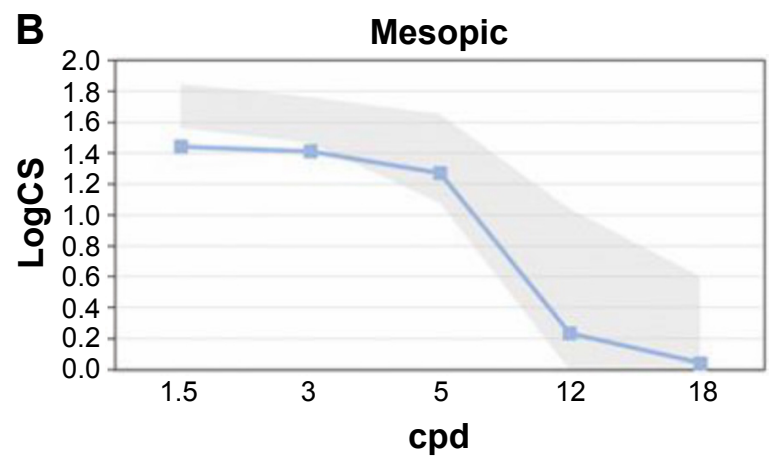

Figure 2 Three-month postoperative photopic (A) and mesopic (B) contrast sensitivity.

Note: The gray areas represent the normal ranges of similar age groups under photopic and mesopic conditions. ${ }^{10}$

Abbreviations: CS, contrast sensitivity; cpd, cycles per degree. 


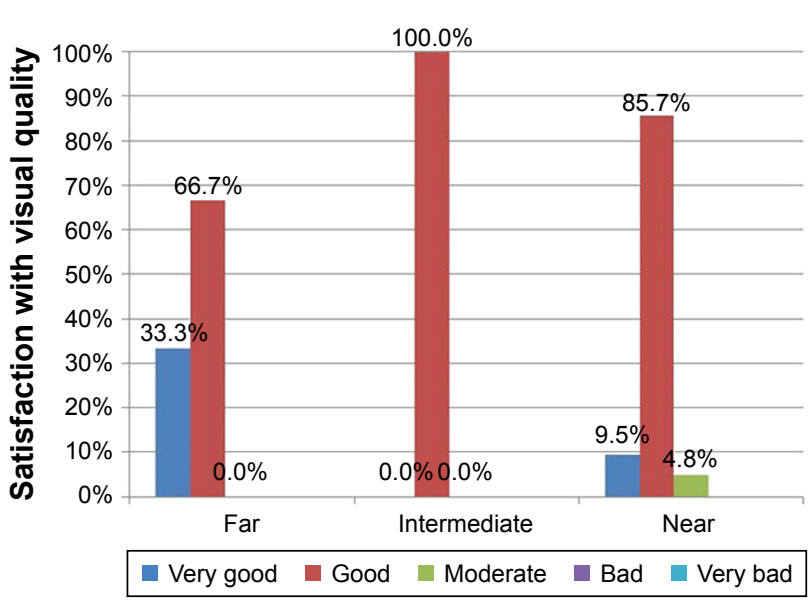

Figure 3 Three-month postoperative patient satisfaction with the achieved visual quality at far, intermediate, and near distances.

modalities of multifocal IOLs on reading performance using different types of standardized tests. ${ }^{20-29}$ Attia et al ${ }^{21}$ found with another type of trifocal IOL a mean uncorrected 3-month binocular RA of $0.06 \log$ MAR (range: $0.23-0.01$ $\log$ MAR), but for a reading distance of $36.5 \mathrm{~cm}$. Indeed, these authors confirmed that there was a significant difference between fixed conventional $(40 \mathrm{~cm})$ and preferred reading distances. ${ }^{21}$ Alió et $\mathrm{al}^{27}$ reported a mean RA of $0.16 \pm 0.08$ $\log$ MAR with the AT LISA bifocal IOL at 1 month after surgery, but using a different homologated test for evaluating the reading speed.

Reading ability provides an important measure to reflect everyday life performance of multifocal IOLs. It is therefore critical for future comparative studies to confirm if the reading performance outcomes obtained with the evaluated trifocal IOL are similar to or better than those obtained with

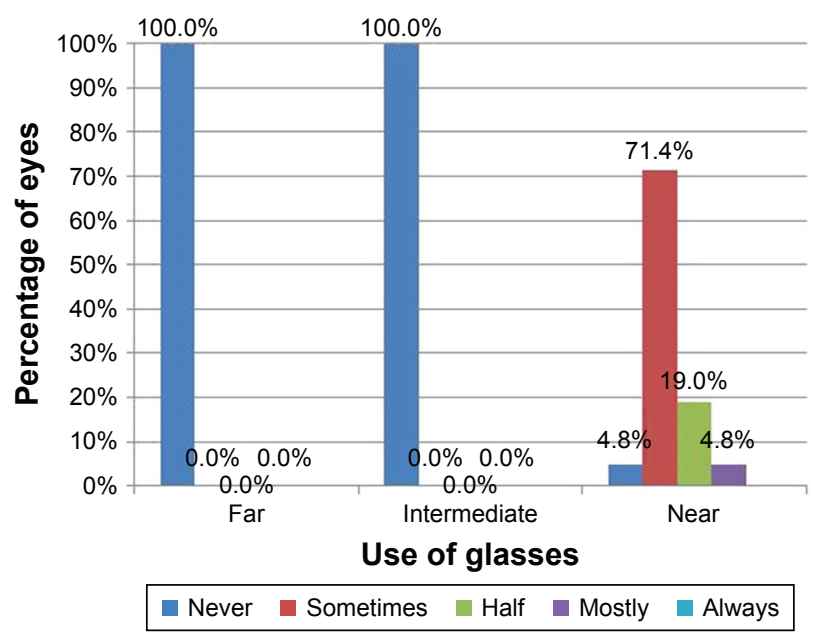

Figure 4 Postoperative frequency of spectacle use at far, intermediate, and near distances. other modalities of multifocal diffractive IOLs. Refractive multifocal IOLs have already been demonstrated to provide poorer reading performance outcomes than diffractive models..$^{26,30}$

Another important parameter to be considered in the evaluation of trifocal IOL outcome could be the reading performance at intermediate distance, which has been recently analyzed for other multifocal IOL types..$^{20,21}$ It would be interesting to evaluate this aspect and to compare the results obtained with different trifocal IOLs.

Besides visual acuity outcomes and reading performance, contrast sensitivity results were also evaluated with the trifocal IOL implanted in our series. Good levels of photopic and mesopic contrast sensitivity were found, as has been reported before. ${ }^{3,5}$ Specifically, the photopic and mesopic contrast sensitivity values obtained at 3 months after surgery in our series were predominantly within the physiological range defined for the healthy population in the same age group. ${ }^{13}$

Finally, patient satisfaction with the visual outcome was very high in our sample, which is consistent with the good visual acuity, reading performance, and contrast sensitivity obtained. Specifically, all patients reported that they would choose the same lens again, and most of them described their visual quality at far, intermediate, and near distances as good or very good. Mendicute et $\mathrm{al}^{7}$ found in another study evaluating the clinical outcomes of the same trifocal IOL platform that more than $90 \%$ of patients were satisfied with the outcome. Likewise, Kohnen et al ${ }^{8}$ confirmed that $92 \%$ of patients implanted with the AT LISA trifocal IOL would choose the same IOL again. This high level of patient satisfaction was greatly influenced by the high levels of postoperative spectacle independence found at all distances, as in the series of Mendicute et $\mathrm{al}^{7}$ with the same trifocal IOL platform.

\section{Conclusion}

The trifocal diffractive IOL evaluated in the current study is able to provide high levels of visual quality, patient satisfaction, and spectacle independence after cataract surgery. The very good visual outcome has a positive impact on reading performance.

\section{Disclosure}

The authors report no conflicts of interest in this work.

\section{References}

1. Cochener B. Prospective clinical comparison of patient outcomes following implantation of trifocal or bifocal intraocular lenses. J Refract Surg. 2016;32:146-151. 
2. Postolache C, Postolache O. Comparation of refractive results with bifocal implants AT LISA 809 and trifocal AT LISA tri839. Rom J Ophthalmol. 2015;59:100-102.

3. Mojzis P, Kukuckova L, Majerova K, Liehneova K, Piñero DP. Comparative analysis of the visual performance after cataract surgery with implantation of a bifocal or trifocal diffractive IOL. J Refract Surg. 2014;30:666-672.

4. Plaza-Puche AB, Alio JL, Sala E, Mojzis P. Impact of low mesopic contrast sensitivity outcomes in different types of modern multifocal intraocular lenses. Eur J Ophthalmol. 2016;26(6):612-617.

5. Mojzis P, Majerova K, Hrckova L, Piñero DP. Implantation of a diffractive trifocal intraocular lens: one-year follow-up. J Cataract Refract Surg. 2015;41:1623-1630.

6. Marques JP, Rosa AM, Quendera B, et al. Quantitative evaluation of visual function 12 months after bilateral implantation of a diffractive trifocal IOL. Eur J Ophthalmol. 2015;25:516-524.

7. Mendicute J, Kapp A, Lévy P, et al. Evaluation of visual outcomes and patient satisfaction after implantation of a diffractive trifocal intraocular lens. J Cataract Refract Surg. 2016;42:203-210.

8. Kohnen T, Titke C, Böhm M. Trifocal intraocular lens implantation to treat visual demands in various distances following lens removal. Am J Ophthalmol. 2016;161:71-77.e1.

9. Sheppard AL, Shah S, Bhatt U, et al. Visual outcomes and subjective experience after bilateral implantation of a new diffractive trifocal intraocular lens. J Cataract Refract Surg. 2013;39:343-349.

10. Bilbao-Calabuig R, Llovet-Rausell A, Ortega-Usobiaga J, et al. Visual outcomes following bilateral implantation of two diffractive trifocal intraocular lenses in 10084 eyes. Am J Ophthalmol. 2017;179: 55-66.

11. Radner W. Near vision examination in presbyopia patients: do we need good homologated near vision charts. Eye Vision. 2016;3:29.

12. Virgili G, Cordaro C, Bigoni A, Crovato S, Cecchini P, Menchini U. Reading acuity in children: evaluation and reliability using MNREAD charts. Invest Ophthalmol Vis Sci. 2004;45:3349-3354.

13. Hohberger B, Laemmer R, Adler W, Juenemann AGM, Horn FK Measuring contrast sensitivity in normal subjects with OPTEC ${ }^{\circledR}$ 6500: influence of age and glare. Graefes Arch Clin Exp Ophthalmol. 2007;245:1805-1814.

14. Mojzis P, Majerova K, Plaza-Puche AB, Hrckova L, Alio JL. Visual outcomes of a new toric trifocal diffractive intraocular lens. J Cataract Refract Surg. 2015;41:2695-2706.

15. Kretz FT, Breyer D, Klabe K, et al. Clinical outcomes after implantation of a trifocal toric intraocular lens. J Refract Surg. 2015;31:504-510.

16. Plaza-Puche AB, Alio JL. Analysis of defocus curves of different modern multifocal intraocular lenses. Eur J Ophthalmol. 2016;26(5): 412-417.

17. Kretz FT, Müller M, Gerl M, et al. Binocular function to increase visual outcome in patients implanted with a diffractive trifocal intraocular lens. BMC Ophthalmol. 2015;15:110.
18. Shen Z, Lin Y, Zhu Y, Liu X, Yan J, Yao K. Clinical comparison of patient outcomes following implantation of trifocal or bifocal intraocular lenses: a systematic review and meta-analysis. Sci Rep. 2017; 7:45337.

19. Gundersen KG, Potvin R. Trifocal intraocular lenses: a comparison of the visual performance and quality of vision provided by two different lens designs. Clin Ophthalmol. 2017;11:1081-1087.

20. Attia MS, Khoramnia R, Auffarth GU, Kirchner M, Holzer MP. Near and intermediate visual and reading performance of patients with a multifocal apodized diffractive intraocular lens using an electronic reading desk. J Cataract Refract Surg. 2016;42:582-590.

21. Attia MS, Auffarth GU, Khoramnia R, Linz K, Kretz FT. Near and intermediate reading performance of a diffractive trifocal intraocular lens using a reading desk. J Cataract Refract Surg. 2015;41: 2707-2714

22. Liekfeld A, Ehmer A, Schröter U. Visual function and reading speed after bilateral implantation of 2 types of diffractive multifocal intraocular lenses: add-on versus capsular bag design. J Cataract Refract Surg. 2015;41:2107-2114

23. Maurino V, Allan BD, Rubin GS, et al; Moorfields IOL Study Group. Quality of vision after bilateral multifocal intraocular lens implantation: a randomized trial - AT LISA 809M versus AcrySof ReSTOR SN6AD1. Ophthalmology. 2015;122:700-710.

24. Schmickler S, Bautista CP, Goes F, Shah S, Wolffsohn JS. Clinical evaluation of a multifocal aspheric diffractive intraocular lens. $\mathrm{Br} J$ Ophthalmol. 2013;97:1560-1564.

25. Rasp M, Bachernegg A, Seyeddain O, et al. Bilateral reading performance of 4 multifocal intraocular lens models and a monofocal intraocular lens under bright lighting conditions. J Cataract Refract Surg. 2012; 38:1950-1961.

26. Alió JL, Grabner G, Plaza-Puche AB, et al. Postoperative bilateral reading performance with 4 intraocular lens models: six-month results. $J$ Cataract Refract Surg. 2011;37:842-852.

27. Alió JL, Plaza-Puche AB, Piñero DP, et al. Optical analysis, reading performance, and quality-of-life evaluation after implantation of a diffractive multifocal intraocular lens. J Cataract Refract Surg. 2011;37:27-37.

28. Akkuş ÖG, Petriçli IS. Comparison of visual outcomes and reading performance after bilateral implantation of multifocal intraocular lenses with bilateral monofocal intraocular lenses. Int Ophthalmol. Epub 2017 May 18.

29. Cillino G, Casuccio A, Pasti M, Bono V, Mencucci R, Cillino S Working-age cataract patients: visual results, reading performance, and quality of life with three diffractive multifocal intraocular lenses Ophthalmology. 2014;121:34-44.

30. Van der Linden JW, van Velthoven M, van der Meulen I, Nieuwendaal C, Mourits M, Lapid-Gortzak R. Comparison of a new-generation sectorial addition multifocal intraocular lens and a diffractive apodized multifocal intraocular lens. J Cataract Refract Surg. 2012;38:68-73.
Clinical Ophthalmology

\section{Publish your work in this journal}

Clinical Ophthalmology is an international, peer-reviewed journal covering all subspecialties within ophthalmology. Key topics include: Optometry; Visual science; Pharmacology and drug therapy in eye diseases; Basic Sciences; Primary and Secondary eye care; Patient Safety and Quality of Care Improvements. This journal is indexed on Submit your manuscript here: http://www.dovepress.com/clinical-ophthalmology-journal

\section{Dovepress}

PubMed Central and CAS, and is the official journal of The Society of Clinical Ophthalmology (SCO). The manuscript management system is completely online and includes a very quick and fair peer-review system, which is all easy to use. Visit http://www.dovepress.com/ testimonials.php to read real quotes from published authors. 